\title{
Reflexión sobre los fundamentos filosóficos de la libertad para la construcción de su hermenéutica libertaria*
}

\author{
Lina María Herrera Montoya \\ Universidad Pontificia Bolivariana, Medellín, Colombia \\ linamhm@gmail.com
}

\section{RESUMEN}

El discernimiento de las valoraciones de la libertad como causa humana requiere un recorrido genealógico que permite ubicar los pilares epistemológicos a partir de los cuales se edifican los discursos que hacen de la libertad una categoría en permanente dinamismo semántico. Para este trayecto de reflexiones se direcciona una hermenéutica filosófica desde un enfoque semiótico que atraviesa el espíritu de la época del siglo XVIII al momento presente y sus implicaciones en el desarrollo cognitivo y actitudinal de los sujetos en esta experiencia. En esta perspectiva, interrogar la semántica de valor del concepto libertad está asociado a un análisis enunciativo que responde a las premisas del momento histórico y a las improntas ideológicas con las cuales la libertad pasa a ser manipulada para delinear una imagen del proyecto antropológico de la sociedad. En esta problematización, la plasticidad del significante y del significado constituye el fundamento dialéctico para pensar los problemas de la lingüística y el devenir histórico en su sentido de cambio y transformación y, por ello mismo, el carácter vaporoso de la cosa y su sentido que da lugar a un planteamiento ético de la libertad en retorno al ethos como expresión vital que desenmascara las pretensiones de control expuestas en los sentidos de libertad posicionados por las lógicas de poder-saber dominantes. Por ello, desde las tensiones filosóficas y hegemónicas, la reflexión que se plantea se arriesga a concebir la libertad como un universal que atraviesa el sentido y la experiencia de la existencia humana sin las determinaciones políticas y económicas que la manipulan.

Palabras clave: libertad; cultura; el otro; Ilustración; Estado moderno.

Cómo citar: Herrera Montoya, L. (2021). Reflexión sobre los fundamentos filosóficos de la libertad para la construcción de su hermenéutica libertaria. Ciencias Sociales y Educación, 10(20), 213-240. https://doi.org/10.22395/ csye.v10n20a10

Recibido: 6 de abril de 2021.

Aprobado: 10 de junio de 2021. 


\section{Reflection on the Philosophical Foundations for the Construction of a Libertarian Hermeneutics}

\section{ABSTRACT}

The discernment of the valuations of freedom as a human cause supposes a genealogical journey that allows locating the epistemological pillars, from whom the discourses that make freedom a class in permanent semantic dynamism are built. For this course of dissertations, a hermeneutic is directed that crosses the spirit of the time from the 18th century to the present moment and its implications in the cognitive and attitudinal development of the subjects in this experience. In this perspective, questioning the value semantics of the concept of freedom is associated with an enunciating analysis that responds to the premises of the historical moment and to the ideological imprints with which freedom begins to be manipulated to de- lineate an image of the anthropological project of society. In this problematization, the plasticity of the signifier and the signified; the vaporous character of the thing and its meaning gives rise to an ethical approach to freedom in return to ethos as a vital expression that unmasks the claims of control exposed in the senses of freedom positioned by the dominant logic of power-knowledge. Thus, from the philosophical and hegemonic tensions, the reflection that arises risks conceiving freedom as a universal that crosses the meaning and experience of human existence without the political and economic determinations that alter it.

Keywords: freedom; culture; the other; age of enlightenment; the Modern state.

\section{Reflexão sobre os fundamentos filosóficos da liberdade para construção hermenêutica lihertária}

\section{RESUMO}

O discernimento das valorizações da liberdade como causa humana supõe um percurso genealógico que permite localizar os pilares epistemológicos, a partir dos quais se constroem os discursos que fazem da liberdade uma classe em permanente dinamismo semântico. Para este curso de dissertações, é direcionada uma hermenêutica que atravessa o espírito da época do século XVIII ao momento presente e suas implicações no desenvolvimento cognitivo e atitudinal dos sujeitos dessa experiência. Nessa perspectiva, o questionamento da semântica de valores do conceito de liberdade está associado a uma análise enunciativa que responde às premissas do momento histórico e às marcas ideológicas com as quais a liberdade passa a ser manipulada para delinear uma imagem do projeto antropológico de sociedade. Nessa problematização, a plasticidade do significante e do significado; o caráter vaporoso da coisa e seu significado dá origem a uma abordagem ética da liberdade em retorno ao ethos como uma expressão vital que desmascara as reivindicações de controle expostas nos sentidos de liberdade posicionados pela lógica dominante do poder-conhecimento. Assim, a partir das tensões filosóficas e hegemônicas, a reflexão que surge corre o risco de conceber a liberdade como um universal que atravessa o sentido e a experiência da existência humana sem as determinações políticas e econômicas que a alteram.

Palavras-chave: liberdade; cultura; o outro; Idade da iluminação; o Estado Moderno. 


\section{Introducción}

Pensar la libertad como causa humana implica volver la mirada al valor en tanto cualidad dominante de los discursos; no solamente como aquel dado por las vacilaciones filosóficas y su pretensión de verdad a través de esencialismos ontocéntricos, teocéntricos, glotocéntricos, antropocéntricos y semiocéntricos, sino como aquel que se instala y se enuncia desde un lugar de poder. Consecuentemente con este propósito, responder a esta exigencia también es atender a una manera de hacerlo, es decir, a una genealogía para ocuparse de la libertad en tanto que es experiencia que se construye en un modo de ser y decir, en otras palabras, en un ethos y en las ideas que dirigen la existencia.

De acuerdo con lo anterior, en el presente texto se busca rastrear la libertad en algunas de sus valoraciones asentadas en criterios fundamentalistas que determinan modos y maneras de ser y aparecer en el mundo y en las diversas realidades que su materialidad e historicidad sugieren. Estos criterios son rectores de la libertad en los códigos de moralidad y urbanidad intolerantes con los despliegues de la voluntad y el deseo que asisten al ser humano. Son criterios de mesura, equilibrio y armonía que inscriben la libertad en una performatividad de contemplación y experiencia estética; criterios conductuales y cognitivistas que rentabilizan e instrumentalizan la libertad en las directrices del mercado y en la capacidad adquisitiva; criterios anarquistas, demoledores y depredadores de a libertad como máxima expresión del libre albedrío. A partir de allí, se configuró el modo en sus matrices epistemológicas así como en las vicisitudes sociales y económicas de la época.

La genealogía permitirá desvelar el talante de la libertad tal como hoy es concebida en la formulación de dos preguntas: ¿Cómo y a qué circunstancias sociales y discursivas del momento actual obedece la constitución de la libertad del siglo XVIII? Del lado de esto y a partir de que el entorno histórico es un elemento a considerar para este estudio, la meditación sobre los fundamentos filosóficos de la libertad, en sus continuidades y discontinuidades, con sus pretensiones de verdad y en sus intenciones de responder a la contingencia de la existencia, deberá preguntarse cómo las concepciones filosóficas de la libertad a partir del siglo XVIII legitimaron la experiencia de su valoración vigente. Responder a dichos interrogantes implica, entonces, analizar el lugar desde donde se enuncian las apreciaciones valorativas de la libertad, el lenguaje mismo que media la intención de nombrar y conceptualizar. De ahí que la interpretación de alguna manera de decir permita la comprensión, no solo de su génesis, sino de sus transformaciones y de la forma en que dirigen la voluntad y pensamiento de quienes la experimentan. Más aún, atreverse a retirar el halo de beatitud del valor: lo valioso, lo es, ¿para qué?, ¿para quién?, ¿cómo? ¿y de qué manera cooperan estas fuerzas, dialoguen entre sí o no? 
En este sentido, el otorgamiento del valor a la libertad ha supuesto todo un devenir de apreciaciones sujetas a la apropiación de su coseidad como criterio de manipulación en conformidad con el lugar físico y simbólico. Este determina el paisaje semántico valorativo de esta experiencia que implica, en la historia humana, evidenciar la relatividad con la cual la libertad permanece en dinamismo de sentido:

\begin{abstract}
El 'desarrollo' de una cosa, de un uso, de un órgano es, según esto, cualquier cosa antes de su progressus hacia una meta, y menos aún un progreso lógico y brevísimo, conseguido con el mínimo gasto de fuerza y de costes, sino la sucesión de procesos de avasallamiento más o menos profundos, más o menos independientes entre sí, que tienen lugar en la cosa, a lo que hay que añadir las resistencias utilizadas en cada caso para contrarrestarlos, las metamorfosis intentadas con una finalidad de defensa y de reacción, así como los resultados de contradicciones afortunadas. La forma es fluida, pero el 'sentido' lo es todavía más... Incluso en el interior de cada organismo singular las cosas no ocurren de manera distinta: con cada crecimiento esencial del todo cambia también de 'sentido' de cada uno de los órganos. (Nietzsche, 2014, pp. 112-113)
\end{abstract}

Desde esta perspectiva, el análisis de la libertad daría cuenta de una amalgama de sentidos, de un campo semántico cuyo origen no puede rastrearse en un orden lógico, cronológico o de utilidad. Por el contrario, su estudio puede, a lo sumo, reconstruir el concepto en la autorización dialéctica de otorgarle " diferente significado a unas mismas palabras y expresiones en dependencia de la clase a que pertenezca" (Stalin, 1976, p. 38). De este modo, se puede comprender qué elementos la modifican, en qué proporción y, a la postre, plantear nuevas discusiones y valoraciones en el rigor ético "que no desatiende el orden de los acontecimientos o los 'descubrimientos gramaticales' [...] de un sentido de la localización en el espacio dialéctico o en el tiempo histórico" (Rorty, 1989, p. 163).

En este cuadro de apreciaciones iniciales, rastrear, registrar y reflexionar las valoraciones de la libertad como causa humana constituirá emprender un recorrido por los referentes genealógicos que apoyan las preguntas y las construcciones de sentido que dan origen a las versiones epistemológicas que comunican, desde el siglo XVIII hasta el momento actual, las pretensiones que han acompañado el devenir histórico en sus improntas político-económicas direccionadas por el capitalismo. Este recorrido histórico atraviesa el ideal de la ilustración como discurso antropocéntrico que erige la supremacía de la razón instrumental definiendo e imponiendo concepciones que diseñan formas de actuación y de comprensión de la realidad.

En este acontecer histórico, la libertad se expone a una permanente mutación semántica que sugiere un trayecto de reflexiones que serán direccionadas desde una hermenéutica filosófica con enfoque semiótico. De esta manera, se 
atraviesa el espíritu de la época del siglo XVIII al momento presente y sus implicaciones en el desarrollo cognitivo y actitudinal de los sujetos en esta experiencia. En esta perspectiva, interrogar la semántica de valor del concepto de libertad está asociado a un análisis enunciativo que responde a las premisas del momento histórico y a las improntas ideológicas con las cuales la libertad pasa a ser manipulada para delinear una imagen del proyecto antropológico de la sociedad.

En esta problematización, la plasticidad del significante y del significado constituye el fundamento dialéctico para pensar los problemas de la lingüística y el devenir histórico en su sentido de cambio y transformación. Por ello mismo, el carácter vaporoso de la cosa y su sentido que da lugar a un planteamiento ético de la libertad en retorno al ethos como expresión vital que desenmascara las pretensiones de control expuestas en los sentidos de libertad posicionados por las lógicas de poder-saber dominantes. Así las cosas, desde las tensiones filosóficas y hegemónicas, la reflexión que se plantea se arriesga a concebir la libertad como un universal que atraviesa el sentido y la experiencia de la existencia humana sin las determinaciones políticas y económicas que la manipulan.

Con el propósito de recorrer los móviles semánticos de la construcción histórica del valor de la libertad, este primer capítulo transitará los soportes ideológicos del capitalismo que perfilan el proyecto humano hacia los sentidos y actitudes individualistas sostenidos por el liberalismo. Este proyecto declara la abolición de todas las formas coercitivas frente a las potencialidades que se buscan poner en acto las pretensiones económicas de los individuos. Esta actitud se refuerza en la transición al neoliberalismo con la flexibilidad de todos los mecanismos de mercado que le dan intervención al capital privado y limitación de las facultades del Estado en el devenir y en las dinámicas de la economía. En esta ley del más fuerte descansa también la idea del sálvese quien pueda $\mathrm{y}$, con ello, el abandono de todos los vínculos fraternales que hagan pensar en una idea colectiva del bienestar y la justicia en la experiencia de la libertad.

\section{Breve reconstrucción histórica de la lihertad desde el siglo XVIII hasta la actualidad}

En la pesquisa del valor semántico de la libertad parece hallarse un punto común en el que los pensadores y filósofos, que se ocupan de ella, se encuentran: el cariz de desarrollo que ha tenido el capitalismo. Los horizontes ideológicos del problema han sido abordados en la perspectiva de diferentes perspectivas discursivas, como la religión, la sicología o la economía política. Pero todos ellos han apuntado a una relación insoslayable y estrecha con el capitalismo en sus posteriores formas liberales y neoliberales. Asimismo, se configura el individuo a partir de dichas elaboraciones económicas. Si bien la discusión sobre el 
capitalismo y la manera en que encontró un terreno propicio para desarrollarse no constituye el núcleo del problema que aquí se trata de abarcar, se hace ineludible al momento de rastrear el sentido o agrupación de sentidos en lo que a la libertad se refiere.

De acuerdo con Weber (2011), el crecimiento de las comunidades protestantes en los Estados Unidos de América y la adopción de la concepción de conducción de vida de estos grupos tuvieron un fuerte impacto en la manera como el capitalismo, el cual se refiere a una praxis económica rastreable desde la antigüedad, se comportaría así desde el siglo XVIII hasta nuestros días. Lo que interesa del estudio del autor es, precisamente, cómo las ideas pueden participar y modificar los procesos sociales. Respecto a esto, Weber (2011), en La ética protestante y el espíritu del capitalismo, aclara que no desconoce el materialismo dialéctico en la manera en que se afectan y entretejen los acontecimientos, las sociedades, las ideologías, las ciencias y las técnicas. Pero advierte que las ideas, como una suerte de guardagujas, transforman, además, la conducción de los procesos sociales. En el mismo libro, el sociólogo sitúa el problema en las comunidades religiosas procedentes del calvinismo: su ascesis, modo de conducción de vida, actividad económica y su motivación para ello; la vía religiosa racional para la conducción de vida. Ello procede de la angustia experimentada por la creencia en un dios, monoteísta y cristiano, que antes de la creación ha elegido a las almas con acceso a la salvación y que no puede ser interpelado por ningún mecanismo mágico como en el caso del catolicismo con sus sacramentos. Al mismo tiempo, está la certeza sobre el peligro de la falta de fe que puede ir en detrimento del estado de gracia.

En consecuencia, el religioso protestante se encuentra en la necesidad de encontrar algún mecanismo, no mágico, para encarar su angustia y se plantea "un método sistemático y racional de conducción de vida, con el fin de superar el status naturae" (Weber, 2011, p. 169). Este método no solo promete apaciguar la angustia, sino que, en adición, se constituye en sí mismo como vía para la única libertad posible del ser humano. Así, se sustrae al ser humano del poder de los apetitos irracionales y se le devuelve su libertad ante el mundo y la naturaleza. De ese modo se aseguraba la primacía de la voluntad planificada, se sometían acciones a permanente autocontrol, se educaba (objetivamente) al monje como trabajador al servicio del reino de Dios y (subjetivamente) se le aseguraba, a su vez, la salvación del alma (Weber, 2011, p. 169).

Así, esta conquistada libertad, indiferente al mundo y sus concupiscencias, fue alcanzada y garantizada por el arduo trabajo y con el ocio como enemigo de la permanencia en el estado de gracia y la gloria del dios protestante; la constancia en la profesión, es decir, la ocupación asumida como llamado y precepto 
divino, mas no como destino; en el fiel ejercicio de la virtud como ocupación del tiempo en tareas que salvaguarden el estado de gracia, honestidad en los negocios, persistencia en la oración, el deber; y en la práctica de la sencillez que evita el gasto de las ganancias obtenidas por el trabajo para efectos mundanos y dejando como feliz consecuencia para el desarrollo del capitalismo, como hoy lo conocemos, la acumulación de grandes capitales.

No obstante, aun cuando este espíritu configuró la eticidad del capitalismo moderno, según Weber (2011), hubo un vaciamiento de este. En su lugar, el capitalismo y su ética político-social descansa en "fundamentos mecánicos" (Weber, 2011, p. 248). La acumulación de capital, despojada de la regulación operada por la religión, ha dejado algo más en su lugar: el ejercicio de las actividades económicas como coacción en ese despojo de las ideas religiosas (Weber, 2011) no deja claro el sentido y el valor de lo que se hace más que para obedecer a las pasiones que tanto desagradaron a los capitalistas protestantes. Frente a esto cabe preguntar: ¿qué transformaciones tendrá la libertad en su despojamiento del espíritu del que habló Weber? Paralelo a lo anterior, el acontecimiento de la libertad tiene un análisis que se ofrece a partir de la economía política, el surgimiento de la población y con un Estado que ya no precisa intervenir sobre la multiplicidad de individuos. En su lugar, su campo de acción e intervención se desplazaría a la población, esto es, al colectivo que se define como comportamiento, "medio de vida, de existencia, de trabajo" (Foucault, 2006, p. 46). En el contexto del Estado neoliberal de la población, el contrato social inscribe a los individuos en la regulación desde el previo acontecer de contradicciones que el liberalismo ofrece al individuo en su despliegue como medida de todas las cosas, como valor antropocéntrico que declara autosuficiencia en la máxima expresión de la ideología individualista de masas y, por consiguiente, en el reforzamiento filosófico, político y económico que hace de la libertad el criterio de negación a todo impedimento o limitación del apetito consumista del individuo.

Siendo esto así, la libertad del individuo de este Estado no solo obedecería a las lógicas del libre comercio, sino, al tiempo, a "la introducción de los dispositivos de seguridad" (Foucault, 2006, p. 71). Esto se debe a que el sistema neoliberal mismo descansa sobre los cimientos del liberalismo y su "dejar hacer, pasar y transcurrir" (Foucault, 2006, p. 70). Este hecho sugiere una completa dependencia de la libertad como tecnología de poder y dispositivo de seguridad que administra y redirige la voluntad del individuo de acuerdo con el contrato social. Entonces, cabe preguntarse: ¿cómo se hará esto?, ¿cómo se administrará y redirigirá la voluntad del individuo del contrato social en el neoliberalismo? Se hará mediante el deseo, por supuesto, dado que "la naturalidad del deseo marca la población y la técnica gubernamental puede penetrarlo" (Foucault, 2006, p. 96). Esto se propone desde un deseo que fluye dentro "de determinados 
límites y en virtud de una serie de relaciones y conexiones" (Foucault, 2006, p. 96) que "redundará en suma en el interés general de la población. El deseo es la búsqueda del interés para el individuo" (Foucault, 2006, p. 96).

No obstante, la libertad en el marco de esta trama ya no tendrá la sencillez de la máxima que Adam Smith (2011) expuso en La riqueza de las naciones cuando aseguraba que "toda persona, en tanto no viole las leyes de la justicia, queda en perfecta libertad para perseguir su propio interés" (Smith, 2017, pp. 659-660). Con esta afirmación, hace frente a los abusos de la monarquía sobre el pueblo sujeto a la arbitrariedad de sus edictos, los cuales forzaban al hambre y a cualquier tipo de precariedad. Por el contrario, la libertad neoliberal se fundamenta en adquirir un cariz individualista y, al tiempo, homogeneizador: ¿cómo hacer del interés, o mejor, del deseo, algo "interesante para la propia población" (Foucault, 2006, p. 96)? Es aquí, precisamente, donde la libertad se cubre de las valoraciones necesarias para que el individuo desee, de la manera más adecuada y pertinente, al colectivo que se administra. Hablamos ya de la libertad de interesarse en todo aquello que sea útil para la población, que no es otra cosa que el público y "el espacio pertinente dentro del cual y con respecto al cual se debe actuar" (Foucault, 2006, p. 102). Y, evidentemente, el propio lenguaje que habla de administración y actuación sobre nos permite entrever el criterio que dirige todo este proceso social y político: la economía política, gobierno de las cosas, gobierno que se relaciona "con una suerte de complejo constituido por los hombres y las cosas" (Foucault, 2006, p. 122) y sus respectivas maneras de relacionarse. En últimas, el saber de todo este complejo entramado se vale de diferentes instrumentos, tales como la economía, los dispositivos de seguridad o regulación, la gubernamentalidad con sus "instituciones, los procedimientos, análisis y reflexiones, los cálculos y las tácticas" (Foucault, 2006, p. 136) que le son propias y, finalmente, para el propósito de este texto, la libertad. Aquella es calculada, medida y razonada por y para la organización de poder del Estado de la economía política.

Dado que desde aquí hablamos del gobierno de la población en relación con "las cosas", el Estado de la economía política encuentra la necesidad de intervenir y conducir el modo en que esta se las ve con la realidad económica, social, política y cultural. Aquí encontramos, entonces, la intervención y manipulación del gobierno en la opinión pública que se justifica en el hecho de que "el Estado busca su propio bien y no tiene finalidad exterior alguna, es decir que no puede desembocar en otra cosa que sí mismo" (Foucault, 2006, p. 333). Siendo esto así, es lícito pensar que la libertad habrá de subordinarse a esta máxima, se dirigirá y valorará como una tecnología de poder sobre la cual se levanta un régimen de verdad que habrá de ser impuesta y, por tanto, aceptada y obedecida. Se tratará, pues, de la libertad supeditada a un arte de gobernar 
que va a consistir, "no en recuperar una esencia o permanecer fiel a ella, sino en manipular, mantener, distribuir, restablecer relaciones de fuerza, y hacerlo en un espacio de competencia que implica un desarrollo competitivo" (Foucault, 2006, pp. 355-356).

En este sentido, encontramos una libertad instrumentalizada para los fines del gobierno de la economía política. Desde esta perspectiva, vemos a un Estado que se adjudica "una función moral" (Foucault, 2006, p. 368) que, además, se vincula con "la manera de conducirse de la gente en lo concerniente a sus riquezas y su modo de trabajar y consumir" (Foucault, 2006, p. 369). Con este fin, la demagogia e instituciones estatales se ocupan de dar forma a la relación del ser humano con las cosas, de modo que esta vaya en dirección a un fin común: el Estado. Así, la profesionalización, la moral, la producción y el consumo se dirigen con un criterio unificado y calculado por la razón del Estado para el Estado. De aquí que, como parte de la esfera que compete a este gobierno, la profesionalización y el trabajo respondan a la utilidad que sirva al Estado y a su fortalecimiento; educación e instrucción de personas laboriosas que ejecuten las actividades necesarias para su beneficio.

Para tales propósitos, la gubernamentalidad tendrá que disponerse a intervenir sobre distintas variables que se precisan para hacer manifiesto este plan de gobierno: el crecimiento de la densidad de la población, el trabajo como actividad del hombre por antonomasia y los salarios bajos para el beneficio comercial estatal. De acuerdo con esto, la existencia humana, la moral y la cultura adquieren un valor de cambio y mercancía. Respecto a la moral, la libertad pasa, desde aquí, por la especificidad de la libertad de comercio, la libertad para el juego de la competencia y la libertad de consumo.

En esta perspectiva, las actividades y la manera en que los hombres se relacionan con las cosas pasarían a ser reguladas, ya no por el Estado, sino por la economía que, a su vez, regularía al mismo Estado. La economía, entonces, se configuraría como la "nueva razón gubernamental" (Foucault, 2006, p. 397). Sin embargo, esto no implica que el Estado desaparece, sino que procedería desde una gubernamentalidad, "esbozada por los economistas, [que] siempre se tratará de asignarse como objetivo el aumento de las fuerzas del Estado en el marco de cierto equilibrio" (Foucault, 2006, p. 399). Y, dado que una razón de Estado configurada por la economía — cuyas prácticas económicas apelan al interés individual y a la competencia- precisa de ciertos mecanismos para su suelto desenvolvimiento, nos ponemos de frente con la libertad misma como garante del proceso económico y estatal. De ahí que la libertad comience a sufrir una serie de especificidades con el fin de operar sobre los intereses de la población y, así, dirigir las actividades y el deseo del individuo a la concreción 
del proyecto de la economía política. Estas especificidades amplían el campo semántico de la libertad y, a su vez, implican limitaciones para su ejercicio. De este modo, surge el concepto de libertades.

Pero, antes de pasar a dicha categoría, se debe seguir interrogando la economía política a partir del presupuesto de la inexistencia de los universales. Como principios axiológicos de la verdad y la bondad, estos permitirían pensar los cimientos políticos de la dignidad y la justicia para respaldar un sentido de apropiación común de la libertad, es decir, una semántica que, aún en su despliegue de posibilidades, asienta a la experiencia humana en el derecho a concebir que no hay libertad sin justicia social ni sin la consideración digna de pertenecer a una sociedad en la que todos nos sintamos representados e identificados y, de esta manera, poder resituar la pregunta en las prácticas gubernamentales, sociales, culturales y económicas. La economía política misma ha permeado dichas prácticas, las ha conducido e institucionalizado o rechazado. De ahí que sea esta quien responda sobre la libertad, no como universal, sino como práctica "para preguntar qué historia puede hacerse" (Foucault, 2007, p. 19). Este cuestionamiento se hace, entonces, desde el contexto del Estado de la economía política a partir del siglo XVIII, la cual preconfigura las prácticas sociales en su conjunto tal y como hoy las conocemos. Para responder a esto, se considera una forma de gobernar que "se propone el enriquecimiento del Estado" (Foucault, 2007, p. 31) y "garantizar de manera conveniente, ajustada y siempre beneficiosa la competencia entre los Estados" (Foucault, 2007, p. 31).

En el siguiente capítulo se retoman los elementos que ambientan el espíritu de la ilustración como ideal de un individuo regulado por las facultades racionales que conducen las acciones y los sentidos por las sendas de un imaginario científico en apropiación, control y definición de la naturaleza. El horizonte de la libertad toma las rutas teóricas alimentadas en las perspectivas políticas y económicas del liberalismo que enfatiza en la apertura de un individuo capaz de trazar y cumplir con sus expectativas de habitar cómoda y rentablemente el mundo; de encontrar y permitirse las razones para desafiar los obstáculos en las lógicas de una competencia regulada por la dialéctica del hacer y dejar hacer al otro para que cada uno responda a sus propias expectativas sin los tropiezos propios de una intervención externa. De esta manera, las mismas formas de regulación social se apoyan en la imagen del pacto para explicitar el libre albedrío como condición de posibilidad para que cada individuo forje sus destinos de prosperidad, acumulación y abundancia. En estos avistamientos filosóficos, se eleva ese imaginario abstracto con el cual los seres humanos se representan la vida en un mundo donde fluyen y se concretan todos los proyectos materiales como prescripciones incuestionables para que el capital se mantenga en su ritmo de producción y reproducción en los códigos de la ganancia. 


\section{Aproximación a los fundamentos filosóficos de la libertad en el siglo XVIII hasta nuestros días}

Con los cimientos renacentistas, que se dirigen al hombre como autor y actor de las realidades e idealidades que van configurando la idea del mundo, se tienen los primeros insumos del liberalismo. Este se va perfilando en su forma doctrinaria hasta la imagen del individuo desatado de toda forma de coacción gracias a la revolución industrial como fenómeno propicio para toda la estructuración teórica en las visiones políticas y económicas de Adam Smith y David Ricardo. No obstante, la pulsación antropocéntrica de la ilustración en la actuación determinante de la razón instrumental, al dirigir sus leyes hacia la dominación de la naturaleza y hacia el control de los procesos de producción y reproducción del mercado, constituye el escenario privilegiado que alimenta al liberalismo y a toda su potencialidad en el valor de una libertad que encuentra en la razón las coordenadas para el progreso y la autodeterminación humana.

En esta secuencia argumentativa, alentada por el espíritu crítico de una hermenéutica sostenida en la "reflexión metodológica sobre la pretensión de verdad y el estatuto científico de las ciencias del espíritu" (Grondin, 2008, p. 18), se atienden a los planteamientos filosóficos de la libertad desde la perspectiva del liberalismo. Esta perspectiva se constituye, en principio, en el ideario filosófico de la Ilustración. Momento del pensamiento filosófico dirigido por la razón con las pretensiones y finalidades últimas de la ciencia natural: pasar del rigor sistemático y la pura deducción al análisis del fenómeno que conduce al posterior hallazgo de principios; y a "la auténtica correlación de "sujeto" y "objeto", de "verdad" y de "realidad" (Cassirer, 1972, pp. 23-24). En esta misma perspectiva, tanto el Estado como la sociedad se presentan como realidades susceptibles al análisis. Después de todo, el primero es un "cuerpo" compuesto de hombres que se reúnen para hacer sociedad y un contrato que engendre una voluntad general a partir de la subordinación de las voluntades particulares en nombre del bien común, pues "cada uno de nosotros pone en común su persona y todo su poder bajo la suprema dirección de la voluntad general, recibiendo a cada miembro como parte indivisible del todo" (Rousseau, 2007, p. 17). Ello quizá sea posible, porque el pensamiento analítico parece demostrar que la diversidad en el ser humano, bien sea en la cultura, la moral, la ideología, el arte, entre otros, es manifestación de "un protofenómeno "psíquico en general" (Cassirer, 1972, p. 41). Esto quiere decir que la filosofía de la Ilustración reconoce lo multiforme, lo cambiante y lo diverso; y lo hace aceptándolo como apariencia y como producto de la facultad creativa de un núcleo permanente que toda naturaleza comparte. Aquellos cambios, como contenido de lo fenoménico, son captados sensorialmente y traducidos por la razón que se vale del método analítico para hallar el lenguaje y la estructura del corazón de las cosas; en otras palabras, lo universal. 
En consecuencia, los Estados, como productos del protofenómeno "psíquico en general" (Cassirer, 1972, p. 41), independientemente de su forma de gobierno, deben encaminarse al horizonte de la voluntad general y del derecho como "dictado de la recta razón" (Grocio, 1925, p. 52). Esto implica estar "libre de toda mezcla con el mero poder" (Cassirer, 1972, p. 263). Sin embargo, el giro conceptual y aplicativo del derecho tiene su acento en el modelo matemático, pasando del "terreno de lo fáctico, de lo real y efectivo, al terreno de lo posible" (Cassirer, 1972, p. 264), dado que

No queda otro recurso que intentar descubrir en el absurdo decurso de las cosas humanas un propósito de la naturaleza [...] La naturaleza ha querido que el hombre extraiga por completo de sí mismo todo aquello que sobrepasa la estructuración mecánica de su existencia animal y que no participe de otra felicidad o perfección que la que él mismo, libre del instinto, se haya procurado por medio de la propia razón. (Kant, 2004, p. 105)

Ese estar libre del instinto, con el fin de procurarse la propia felicidad, pone su acento en un entendimiento y aplicación del derecho que piensa la libertad como "percepción de la necesidad racional" (Berlin, 2014, p. 97). Por ende, el Estado, el cual "no es un patrimonio" (Kant, 2016, p. 73), sino "una sociedad de hombres sobre la que nadie más que ella misma tiene que mandar y disponer" (Kant, 2016, p. 73), solo tiene lícito ocuparse de la construcción y ejecución de formas jurídicas que, de acuerdo con la Naturaleza, hagan prosperar los nuevos ideales ilustrados basados en el progreso humano y económico. Para ello, debe admitir que cada ser racional persiga el modo de vida y de pensamiento que mejor le parezca, siempre y cuando sean razonables; "por lo tanto, el laissez faire absoluto y la completa organización social difícilmente son incompatibles; de hecho, son idénticos" (Kant, 2016, p. 97).

Al lado de esto, el énfasis moderno en la razón abre la lectura de la libertad como un "deber ser" (Bueno, 1996, p. 238) que descansa en la premisa de esta como el satisfacer las "necesidades racionales" (Bueno, 1996, p. 143). Y que, dado el caso en el que el individuo o las sociedades desconocieran los mandatos de la razón para alcanzar el fin de la libertad, hace legítimo, sin que esto riña con la libertad, el ejercicio del poder sobre los individuos en pro de una praxis y normas de conducta que los haga partícipes de la felicidad del deber-ser ilustrado; obedecer, en este caso, "es mi libertad" (Bueno, 1996, p. 143).

En esta medida, Han (2018e) afirma: "el ciudadano particular no percibe el orden jurídico como si fuera una coerción externa, más bien representa para él su destinación propia. Ese orden jurídico es el único que lo convierte en ciudadano libre" (p. 37). Esto pone en evidencia otra manifestación artificiosa de la posibilidad humana en sus despliegues diversos, pues solamente a través de los ordenamientos ideológicos se perfila una idea de libertad que constriñe la 
complejidad humana en los imaginarios de una ciudadanía diseñada en las lógicas consumistas del mercado.

Encontramos, pues, que la razón legislativa es la moduladora privilegiada de las prácticas humanas; las dirige, acerca y estructura de acuerdo con los designios de la Naturaleza. De esta manera, hace frente a la "secreta operación de causas contrarias" (Hume, 1980, p. 111) que, aparentemente, expone o revela un azar inconmensurable y hace factible su interpretación e intervención. De ahí que el derecho, como centinela de las costumbres y valores universales, participe de una "común humanidad" (Pagden, 2002, p. 79) y de una ley que "es la razón humana en cuanto gobierna a todos los pueblos de la tierra" (Montesquieu, 2007, p. 17). Y, dado que, según Kant (2004), "la razón se desarrolla completamente en la especie" (Kant, p. 104), el Estado y el derecho en su teoría y práctica deben estar en perfecta concordancia con este principio de la Naturaleza, de manera que "el puesto del hilo conductor de la razón no sea ocupado por una desazonante casualidad" (Kant, 2004, p. 104). Ante dicho propósito, surge la urgente pregunta sobre cómo reconciliar las distintas voces que, en apariencia, enuncian distintos propósitos e ideas sobre la vida privada y política en el Estado. Por este motivo, Kant responde con el ideal ilustrado como prerrequisito para la conquista del Estado perfecto en una perspectiva cosmopolita que se constituye en los fundamentos de la autonomía, el deber y la libertad. Tres ejes de acción que se circunscriben dentro de los límites del imperativo categórico "obra como si la máxima de tu acción pudiera convertirse por tu voluntad en una ley universal de la naturaleza" (Kant, 2012, p. 126).

Como puede leerse aquí, encontramos que el hombre, al participar de la vida dentro del Estado, se enmarca en el derecho desde un pacto tácito con la especie o "voluntad general" (Rousseau, 2007, p. 17). A partir de esta, sus disposiciones se concatenan en torno al adalid de la razón desarrollada "por completo en la especie, mas no en el individuo" (Kant, 2004, p. 104). Planteado así, la libertad, como uno de los ejes fundamentales del pacto, puede irse configurando, con confianza, a partir del interés de cada miembro del Estado. En este sentido, reconoce que en cada sujeto habita el código moral que lo dirige en sus búsquedas y acciones sin condicionar o limitar las búsquedas y acciones de los demás. De esta manera, la libertad, como aliento y aliciente para una de las más elevadas conquistas humanas - la felicidad- traza criterios diferenciales que permiten identificarla y diferenciarla, por un lado, como un estado de satisfacción transitoria que responde al poseer o al obtener y, por otro lado, a los estados de complacencia que obedecen a los hechos que hacen sentir lo imaginado y lo vivido como experiencia de trascendencia en cercanía con una vida guiada por la brújula de la bondad, la verdad y la belleza como estados del espíritu. De ahí que se torne coherente la afirmación kantiana: 
Nadie me puede obligar a ser feliz a su modo (tal como él se imagina el bienestar de otros hombres), sino que es lícito a cada uno buscar su felicidad por el camino que mejor le parezca, siempre y cuando no cause perjuicio a la libertad de los demás. (Kant, 2004, pp. 221-222)

Desde aquí, es posible entrever la forma en que la moral política de la Ilustración va dando un contorno cada vez más definido a las formas de gobierno occidentales democráticas que adoptan para sí los fundamentos liberales económicos y deontológicos. En lo tocante a la libertad, no solo encontramos la prescripción deontológica kantiana o la idea rousseana de un contrato social, sino una ampliación de su campo semántico que nos sitúa en la propiedad privada como elemento constitutivo de su ejercicio. La libertad, además de encontrarse regulada por la ley de la naturaleza y cimentada en el consenso que exige el pacto, será también, aunque desde un punto de vista que se distancia de los acuerdos sociales atisbados en Kant y Rousseau, para asentarse en el sentido y el patrimonio privado que autoriza a:

Que cada uno pueda disponer de su persona como mejor le parezca; disponer de sus acciones, posesiones y propiedades según se lo permitan las leyes que le gobiernan, evitando así estar sujeto a los caprichos arbitrarios de otro, y siguiendo su propia voluntad. (Locke, 2014, p. 93)

Con este precedente, la libertad alcanza su punto de inflexión en el interés, en la concepción del ser humano que, como una suerte de fuga natural, busca lo más conveniente y dichoso para sí, pues "todo hombre desea dedicarse a su ocupación y gozar de los frutos de su trabajo y de su propiedad en paz y seguridad, y con el menor gasto posible" (Paine, 1984, p. 207). Para ello, precisa de toda la flexibilidad que otorga el libre albedrío, lo cual implica la superación de todas las coacciones que puedan llegar a cuestionar o limitar el ejercicio y disfrute de sus posesiones.

En adelante, el deontologista, guiado por la brújula moral que ordena su relación con sus pertenencias y aspiraciones, no solo tiene la facultad, sino la obligación de prescribir y analizar el interés de modo que participe tanto de la dicha particular o privada como de la pública o del Estado. Se trata, pues, de concebir un modo de vida en el que cada uno proyecte y ejecute un trazado vital que repose en la pesquisa de la dicha sin desvincularse de la obligación de contribuir con su búsqueda a la felicidad de los miembros del Estado en su conjunto o, de no alcanzar tal expectativa, por lo menos no coartar el derecho ajeno de buscar, a su vez, su propio interés.

La lógica del utilitarismo va a basarse en esta premisa y en la idea reguladora de la razón como custodia que impida "un error de cálculo en la suma de la dicha" (Bentham, 1836, p. 126). Más aún, la libertad ha de enmarcarse en la 
prescripción de lo útil que es "de derecho; y, el derecho resulta de la aplicación del principio de la maximización de la dicha" (Bentham, 1836, p. 108). Pero estas aseveraciones en sí no son sostenibles o moralmente aceptables sin el desarrollo de la virtud en el hombre razonable; no es suficiente, pues, con la obediencia y ejecución de las obligaciones y normas jurídicas. Si la razón es la carta de navegación, la virtud es el timón que mantiene el feliz curso en la búsqueda de la dicha, siempre y cuando conserve "los sentimientos y predisposiciones entrañables a favor de la virtud, así como todo disgusto y aversión con respecto al vicio" (Hume, 2014, p. 42). De esta manera, se asegura la firmeza en la convicción y la práctica de la virtud, ya que "lo que es inteligible, lo que es evidente, lo que es probable, lo que es verdadero produce en nosotros, únicamente, el frío asentimiento de nuestro entendimiento" (Hume, 2014, p. 41).

En este sentido, el hombre razonable y virtuoso difícilmente desacierta respecto a la vida pública y privada mientras persigue su propio interés; gusta, sabe medir y aplicar distintos criterios como medios para este fin sin estropear la materialización de la dicha común, lo cual lo convierte en una especie de adalid de intenciones que buscan generar y mantener un ambiente de armonía en el que puedan fluir los intereses propios y ajenos sin tensiones que puedan perjudicar el logro de los propósitos que allí estén trazados:

la virtud, conforme con la doctrina utilitarista, no es natural y originariamente parte del fin, pero es susceptible de llegar a serlo. En aquellos que la aman desinteresadamente ya lo es, deseándola y apreciándola no como medio para la felicidad, sino como parte de su felicidad. (Mill, 2014, p. 117)

La relación entre virtud y felicidad se establece a partir de los criterios de ausencia del vicio y del dolor (Mill, 2014). Sin el ejercicio juicioso en la virtud, el sufrimiento que se desprende de la intemperancia va a entorpecer cualquier esfuerzo dirigido a la búsqueda de la felicidad pública o privada. En este punto del desarrollo de la teoría utilitarista se mantiene el sentimiento de necesidad de la libertad del individuo como parte del engranaje virtud-felicidad, necesidad de la defensa y constitución del carácter individual, de la legitimidad y validez de sus intereses. Mientras el norte que el hombre persiga sea útil, es decir, tenga convergencia con la categoría de felicidad y con todo lo que ella implica: razón y virtud, le es lícito perseguirlo, pues cualquier intento de imponerle un interés ajeno "podría pecar de excesivo al interferir indebidamente con la libertad y la individualidad humanas" (Mill, 2014, p. 110).

Inadvertidamente, el utilitarismo de Bentham ayuda a conferir un sentido a la libertad que se vincula estrechamente con el interés. El análisis se desprende del individuo deseante, cuya naturaleza es inapelable y que, frente a un discurso meramente descriptivo, se encuentra irremediablemente distante. Esto se debe 
a que, mientras se les habla a los individuos "de deberes, cada uno piensa en los intereses" (Bentham, 1836, p. 9). Y es inadvertido porque, aunque Bentham no se haya ocupado mucho de la libertad, pues no creía en una libertad como "ese orden único y verdadero en que cada alma humana logra su realización completa" (Berlin, 2014, p. 116), como derecho, es el guion que traza los límites que el Estado u otro agente no tienen permitido transgredir en la vida humana individual o colectiva. En este contexto, el Estado actúa como garante jurídico que mantiene la búsqueda de la dicha en sus justas proporciones para que las afectaciones suscitadas por los intereses particulares sean mínimas con respecto a la dicha o felicidad del conjunto. Entonces, cabe preguntarse si la libertad es útil o es condición de posibilidad para que los intereses perseguidos por los individuos puedan cumplirse sin intervenciones que restrinjan el máximo beneficio posible.

Para contestar a este entramado interrogativo, hay que encontrar el puente que vincula a la libertad con los principios utilitaristas. En primer lugar, debe reconocerse la primacía de la utilidad en la formulación política y ética de este proyecto, es decir, la utilidad como fin por antonomasia que subordina otros medios y fines para cumplir con la promesa de la dicha o felicidad colectivas. De este mismo lado, es importante admitir al miembro del Estado y la sociedad civil en calidad de individuo que, con el uso de la razón y expansión en el ejercicio de la virtud, conoce, discrimina con justedad sus intereses y sabe adherirse desde una proyección de sí a la felicidad colectiva. En este último punto, se establece la relación entre la libertad y lo útil: con la expansión individual como artífice del progreso humano en la idea de la minimización del dolor y en el acuerdo tácito que la razón y la virtud resguardan, en el que cada uno se ubica en estado de correspondencia con lo que está deseando, lo que cual significa que cada individuo:

recibirá su debida parte, si tiene la que más particularmente le interesa. A la individualidad debe corresponder la parte de la vida en la que el individuo es el principal interesado; a la sociedad, aquella en la que ella misma esté principalmente interesada. (Mill, 2013, p. 178)

La libertad, pues, es útil y, desde el punto de vista del utilitarismo, se trata de un derecho que promueve diferentes formas de pensamiento y de trabajo. En esta medida, puede esperarse de su ejercicio el florecimiento de "las facultades humanas de percepción, juicio, discernimiento, actividad mental" (Mill, 2013, p. 153) y, con ellas, el mejoramiento de la especie, el progreso que solo la elección fecunda, bien sea elección de asociación, de tradición, de hábitos, entre otros, desde donde las libertades individuales toman forma. Hablamos, entonces, de la libertad como elección. 
Si se acepta esta afirmación, lo que queda es ampliar la discusión sobre la libertad en una intención de organización sociopolítica, es decir, la libertad que pasa de la reflexión filosófica a su entrecruzamiento con categorías estrechamente ligadas a la economía política y al derecho desde el punto de vista gubernamental "como una regla, universal o circunscrita a algunas clases definidas de personas, que deriven su validez de un sistema de derechos, basado en promulgaciones legales específicas, o de la costumbre, o de alguna otra fuente identificable de autoridad humana" (Berlin, 1983, p. 147).

A partir de estos requerimientos, el liberalismo no solo toma su forma como filosofía política, sino como la forma occidental de gobierno aceptada e instaurada sobre los pilares de las libertades y de la igualdad. Respecto a esto último, es necesario aclarar que el liberalismo o por lo menos la escuela que se ha impuesto en los Estados de Occidente, en su promulgación y defensa de la libertad como eje fundamental de su filosofía política, no se conecta "con el deseo de igualdad" (Berlin, 1983, p. 167), por lo menos, no en un sentido globalizante por fuera de la esfera del ejercicio de los "derechos legales y políticos" (Berlin, 1983, p. 165). La igualdad en su concepto y aplicación se subordina a la idea de ciudadanos en condición de igualdad ante la ley para participar de las decisiones que le competen al Estado y de la igualdad de todos los seres humanos que les permite vincularse a las diferentes actividades económicas y sociales legales a su disposición: "libertad de emprender, de publicar, de burlarse, de ejercer la sátira, de cultivar la tierra, de comerciar" (Onfray, 2016, p. 256). Otros ámbitos de igualdad no se contemplan por el riesgo de regular demasiado la vida privada de los ciudadanos y de vulnerar el curso espontáneo de las capacidades humanas y su desarrollo.

En resumen, es la igualdad política y de estatus social por y para la libertad. Mientras los intereses de cada particular sigan la línea expuesta y no vayan en detrimento de las libertades individuales que por derecho se adjudican a todo ciudadano, las desigualdades de otro orden diferente al expuesto no solamente son admisibles, sino lícitas. Ahora bien, hay que tener en cuenta que "no se otorga ninguna prioridad a la libertad como tal, como si el ejercicio de algo denominado 'libertad' tuviese un valor preeminente y fuese el principal si no el único fin de la justicia política y social" (Rawls, s. f., p. 34). De ahí que sea posible ver la escisión de la discusión metafísica sobre la libertad o su desplazamiento hacia el ámbito inteligible y gubernamental. Las complejidades metafísicas y morales, en su dimensión abstracta, son reemplazadas por la materia de derechos civiles y ejercicio de las libertades individuales como la libertad de conciencia y la libertad de asociación. Las libertades, pues, parecen desprenderse de un principio de justicia que subordina a la libertad, pretendiendo salvaguardar, de este modo, el dinamismo y evolución de los gobiernos 
democráticos y del conjunto de individuos que componen dichos Estados. Hasta aquí, la historia de las democracias modernas maduras y emergentes se han basado, epistemológicamente, en el proyecto contractualista moderno. Aunque no se habla de un "contrato social" en la política actual, se conserva la necesidad, por parte de los defensores de la democracia, de continuar con esta idea rectora contemplada, tácita o metafóricamente, en la constitución de todo Estado libre con el fin de proteger a los individuos "de la inseguridad de los derechos" (Nussbaum, 2007, p. 56). En consecuencia, la libertad que se subordina a la justicia se traduce en libertades individuales o, incluso, como el primero de "los dos principios de justicia" (Rawls, s.f., p. 33). Por otro lado, la igualdad como segundo principio garantiza el funcionamiento y crecimiento de "una sociedad que se pretende autosuficiente" (Rawls, s.f., p. 38). Este hecho representa un nuevo problema, para el valor en cuestión a nivel global. En un mundo globalizado, el contractualismo se encuentra limitado para responder ante el fenómeno de interdependencia entre los países que participan de la economía. En este sentido, afirma Nussbaum (2007): “los teóricos clásicos asumieron en todos los casos que los agentes contratantes eran hombres más o menos iguales en capacidad y aptos para desarrollar una actividad económica productiva" (p. 34). Pero si ya no hablamos en términos de hombres, sino de naciones que participan de diferentes intercambios económicos, por ejemplo, llaman la atención los procedimientos y prescripciones que se establecen para la participación de estos y que "perturban tanto las economías internas de las naciones implicadas (en especial, las de los países colonizados pobres) como la salud de las relaciones comerciales que podrían establecerse entre las naciones" (Nussbaum, 2020, p. 184).

Fenómenos como los monopolios, instaurados por parte de las potencias económicas —que con sus prácticas colonizan las economías de los países emergentes a partir de tratados y reglas de juego cuyos beneficios se desplazan en una sola vía-abren preguntas sobre la economía democrática y libre no solo a nivel nacional sino trasnacional. ¿Puede decirse que tales protocolos se fundamentan en términos igualitarios, en el sentido de igualdad en la participación - teniendo en cuenta que muchos de los países, concretamente aquellos en vía de desarrollo, que entran en relación con Estados más fuertes económicamente-, no están considerados como pares por su incapacidad en el desenvolvimiento de la actividad económica? ¿Qué sucede, en este contexto, con los pueblos que no poseen las "capacidades" a la hora de contratar, si es que tal contrato existe, con aquellos que sí? ¿Pueden gozar de la libertad e igualdad política para la toma de decisiones económicas y de su horizonte sociopolítico?

Aunque tales protocolos se fundamentan en términos igualitarios, en el sentido de igualdad en la participación, llama la atención la asimetría desde 
la cual los Estados económicamente fuertes establecen relaciones de orden comercial con los países en vía de desarrollo, cuyo desenvolvimiento en la actividad económica se ve diezmado por las inseguridades jurídicas nacionales e internacionales. Este contexto pone de relieve las "incapacidades" que los pueblos en vía de desarrollo poseen a la hora de contratar, si es que tal contrato existe, con los Estados maduros económica y políticamente. Esto quiere decir que se acentúa la imposibilidad de tomar decisiones económicas beneficiosas dado que no se goza de la libertad e igualdad políticas en la arena comercial internacional.

Y, recordando que "las partes en el contrato social son, ante todo, libres" (Nussbaum, 2020, p. 47), no se pueden considerar democráticas las exigencias y prescripciones de un país a otro si no ha existido previamente un acuerdo en el que ambas partes encuentren beneficio y diálogo con miras a la dignidad humana. El contrato fue pensado hasta los límites de la nación y es aquí donde radica su debilidad para responder por las prácticas y relaciones trasnacionales que afectan de forma profundísima a las economías y democracias en desarrollo (Nussbaum, 2007).

Es notable, pues, el paralelismo de las democracias concretas con respecto a la filosofía de los modernos. Esta filosofía, cuya construcción teórica política del Estado ha puesto el acento en la concepción del ser humano en su dignidad, es decir, como fin y no como medio, ha insistido en el uso de la razón como requisito indispensable para acogerse al contrato social y, con frecuencia, ha dejado de encontrar eco en las democracias en ejercicio de los Estados libres vigentes.

El panorama descrito deja percibir una creciente y progresiva desregulación estatal de los derechos y de la economía en favor del mercado, la cual va configurando una libertad como "instrumento para la realización de los intereses privados" (Habermas y Rawls, 1998, p. 27) que se valen del kitsch y la explotación de las emociones o de la psique para el beneficio de un sistema económico que se conduce sin la moral ilustrada que solía asistirle. Asimismo, con la llegada del neoliberalismo a las democracias emergentes y maduras a partir de la década de los ochenta, se despliega un vaciamiento de los sentidos modernos y liberales de la libertad. En consecuencia, la ideología ilustrada es sustituida por una retórica que continúa haciendo uso de su discurso filosófico-político con un tono distinto. La idea del ser humano como un fin en sí mismo, propio del Siglo de las Luces y del pensamiento liberal, se desplaza hacia la primacía del mercado fundamentado tácitamente en la mano invisible de la naturaleza de Smith y en la defensa de las libertades individuales sin los sentidos éticos que los soportaban. Si el capitalismo significó para el ser humano el surgimiento del individuo moderno despojado del destino y de las determinaciones sociales (Fromm, 2019), el neoliberalismo, como nueva forma de gobierno y de hacer economía, resignifica 
al ser humano y su condición de "sujeto libre" con un espíritu diferente al de sus predecesores. Con un lenguaje bancario y empresarial, transforma la narrativa humana con consecuencias para el ser humano que apenas pueden sospecharse. De ahí que las preguntas sobre la libertad, "liberarse de" (Fromm, 2019, p. 57), "liberarse para" (Fromm, 2019, p. 57) y sobre el sujeto, "que literalmente significa 'estar sometido'" (Han, 2018d, p. 11) — ¿a qué se sujeta o somete?-, se reactualicen para responder a la emergencia del sujeto político del siglo XXI que es usuario y deudor de los valores ilustrados.

Ahora bien, si se acepta que uno de los privilegios de la libertad de los modernos, desde el enfoque del liberalismo, es perseguir el propio interés sin que el Estado obstaculice tal búsqueda o intervenga para imponer un molde distinto al que el individuo designe para sí después de una rigurosa meditación y conciencia de lo que es conveniente para alcanzar la verdadera felicidad; es propio cuestionar al ser humano en su relación consigo mismo y con cada uno de los ámbitos que habita como ser político, económico y social en el siglo presente. Es difícil imaginar un ejercicio de la libertad, en el sentido en el que se ha venido estudiando en este texto, a partir de un conjunto de individuos cuya confianza es depositada en las formas de producción y de consumo para la constitución de modos de ser y de experiencia humana. En este sentido, si la persona es un activo más del sistema neoliberal, pues hoy es considerada como recurso o capital humano y "empresari[a] de sí mism[a]" (Han, 2018d, p. 13), ¿puede aún ser para la libertad?

El neoliberalismo ha transformado la actividad humana y, por ende, al sujeto mismo para hacerlos equiparables al mercado y a su comportamiento, por supuesto, "voluntariamente, sin coacción externa" (Han, 2012, p. 30). La consigna es la completa desregulación estatal de la economía y la internalización del slogan "Yes, we can" (Han, 2012, p. 27), donde "lo social se degrada y hace operacional hasta convertirse en un elemento funcional del proceso de producción" (Han, 2013 , p. 94). Volviendo a la idea del contractualismo, en la cual se fundamenta la existencia de los Estados democráticos maduros y emergentes, la metáfora del contrato social ubica a los seres humanos en un momento de acuerdo, un instante de renuncia y ganancia donde se dejan atrás prácticas de guerra con el otro para dar paso al consenso que permita establecer los vínculos necesarios para una vida en comunidad en la que cada parte se beneficia desde una ligazón con el otro. De ahí que la libertad en este contexto sea "una palabra relacional" (Han, 2018d, p. 13) que disputa con este nuevo sujeto del neoliberalismo cuyas relaciones sociales se basan en la competencia y en la apuesta por un nuevo interés que se desanuda de la colectividad participativa y cooperativa del contrato, es decir, de la imagen de personas que "se entregan libremente al desarrollo de las fuerzas productivas sociales" (Arendt, 2008, p. 174). En contraposición 
a esto, la libertad es una acción que "a diferencia de la fabricación, nunca es posible en aislamiento; estar aislado es lo mismo que carecer de la capacidad de actuar" (Arendt, 2005, p. 211). En este sentido, afirma Han (2018a): "los sujetos neoliberales de la economía no constituyen ningún nosotros capaz de acción común" (p. 31). En consecuencia, el sujeto contemporáneo se encuentra en falta de la aptitud para ser libre.

En oposición a lo afirmado, podría argüirse que hoy asistimos a una época más tolerante y cercana al ideal cosmopolita del Siglo de las Luces, existe más cooperación entre seres humanos a nivel nacional y trasnacional, hemos avanzado en la lucha por las libertades individuales como los derechos de la mujer y de las minorías, el discurso inclusivo y el reconocimiento de las deficiencias a nivel jurídico, que han impactado negativamente la dignidad humana, se han ido subsanando. Aunque en menor o mayor medida esto es cierto, ello no implica que lo humano haya sido respondido como si fuese un proyecto que pudiera concluirse en la confianza de un progreso moral ininterrumpido cuya culminación ya se ha ido alcanzando. La mejora moral precisa de la reflexión y de la acción en el espacio público y gubernamental. Dar por sentados los principios de los modernos sin discusión, vigilancia o actualización de estos, implica un deterioro en el espíritu de los derechos y de los principios políticos cuyo coste en vidas humanas no debería volver a repetirse. Toda democracia libre, que no vele por la defensa de una constitución que salvaguarde la dignidad humana, es susceptible al menoscabo de uno de los ideales más amados e incomprendidos del Siglo de las Luces: la libertad. Después de todo, como afirma Arendt (1996),

el problema de la política y el hecho de que el hombre sea un ser dotado de la posibilidad de obrar tiene que estar vívido sin cesar en nuestra mente cuando hablamos del problema de la libertad, porque la acción y la política, entre todas las capacidades y posibilidades de la vida humana, son las únicas cosas en las que no podemos siquiera pensar sin asumir al menos que la libertad existe, y apenas si podemos abordar un solo tema político sin tratar, implícita o explícitamente, el problema de la libertad del hombre. (pp. 157-158)

Se reitera, pues, el problema de la libertad del individuo como humano, irresoluto, siempre en deuda y construcción, que no puede ser trasladado al ámbito de la lógica de mercado sin convertirse en un oxímoron de sí mismo.

En la intención de este último capítulo aparece la libertad como un concepto que carece de una definición que pueda ser equiparada como categoría de exclusiva pertenencia a una dimensión teórica o práctica regulada por los criterios políticos y económicos de un modo de producción que privilegia la conducta del individuo. La libertad extiende sus tentáculos semánticos. Así, abre horizontes para ser pensada, reflexionada y dialogada dentro de una intertextualidad que integra su experiencia como causa humana, es decir, como legado y acción 
que convoca a los seres humanos a ponerse en correspondencia con otras posibilidades vitales que no desligan la libertad de los sentidos y vivencias de la justicia, la dignidad, el bienestar y la misma vida en acordonamientos fraternales que permiten comprender esta experiencia como una conquista dentro de una sociedad en la que todos puedan sentir un lugar para una vida tejida por las voluntades colectivas capaces de compartir como causa y acto de resistencia con el competir.

\section{La libertad se resitúa como causa humana}

De acuerdo con la línea expuesta, se reconoce en el concepto de libertad un valor en expansión y en articulación semántica que despliega pretensiones ideológicas a través de posturas epistemológicas que van expresando el espíritu de una época desde los cimientos políticos y económicos. Con este criterio, se pone de relieve el acuartelamiento de la sociedad dentro de los postulados que los diferentes modos de producción van trazando para definir una estructura en conveniencia con sus lógicas de división y ordenamientos de clases.

En este sentido, se parte del antecedente de la libertad como "una palabra relacional" (Han, 2018d, p. 13), comunicativa y de "apertura "del ser" (Ricoeur, 2015, p. 64) en un sentido vinculante que, con el otro, renuncia "a una definición de alguna manera monádica de la verdad, donde la verdad sería para cada uno la adecuación de su respuesta a su problemática" (Ricoeur, 2015, p. 65). Se habla, pues, de la libertad en la verdad del diálogo que no solo la "salva del olvido y de la muerte" (Ricoeur, 2015, p. 65), sino que la hace hablar con la voz de la necesidad, la emergencia del sujeto contemporáneo y el hombre por venir. El giro que se propone aquí está en la dirección de la cultura, de nuestro "acontecimiento cultural" (Ricoeur, 2015, p. 195), como mediadora en el debate político y como intercambio generador de libertad en concordancia con una praxis jurídica que asuma una postura crítica del ideario ilustrado que soporta, en mayor o menor medida, nuestras democracias.

Como toda filosofía, el discurso responde a un momento histórico y a sus propios afanes. Con la pretensión cosmopolita del Siglo de las Luces se pretendió unificar a los individuos en una voluntad general de progreso, razón, ciencia y dicha. Pero esta se ha visto limitada para responder por sí misma a los avatares de una posmodernidad que se plantea preguntas con posibilidades que franquean lo considerado verosímil en casi cualquier ámbito de la vida diaria. Una época transgresora de la tradición y los valores, la lógica binaria y de los mismos límites de la ciencia y de la técnica exige nuevas resignificaciones que respondan a los peligros y posibilidades que esta realidad supone. 
De hecho, los tejidos semiocéntricos de la posmodernidad que, suponiendo la relación de las partes con el todo, permiten mantener el diálogo entre los códigos del pasado con el presente y en proyección con las pretensiones del futuro, dan cuenta de unos nuevos desafíos de sentido que, a su vez, favorezcan nuevas posibilidades vivenciales de la libertad y, por ende, nuevas rutas interrogativas hacia otras formas de habitar, sentir y reinventar el mundo.

La precipitación de la actividad laboral y social que, gracias a los avances tecnológicos ha acortado distancias y procesos, ha dejado en el camino a la reflexión y al diálogo filosófico-político, cuyo tiempo y espacio son tan propios y tan de otro orden, que no parecen encontrarse para atender a las preguntas fundamentales del hombre contemporáneo. Este sujeto de la Modernidad tardía, asistido por el cansancio del esplendor moderno cifrado por el afán y por la premura de poseer para responder a las afujías de una dinámica indiferente a las doce campanadas vitales (Nietzsche, 2014), ha subvertido, como transgresor que es, los cimientos mismos de la moral ilustrada: por un lado, demanda representación y respeto por toda manifestación individual; por otro, busca imponer una visión totalizante del mundo que se perpetúa en la nostalgia del pasado, defiende y ataca un sistema económico que lo cosifica y agrede, pero se ludifica hasta la saciedad permaneciendo en la minoría de edad denunciada por Kant (2013). Esta minoría declara la incapacidad de elección que constriñe el ejercicio de la libertad en su posicionamiento político de tomar decisiones como posibilidad de establecer renuncias, pues elegir supone descartar y, en esa medida, generar oposición frente a lo que no es deseable o, simplemente, expresar rechazo a una posibilidad que resulta menos tentadora que otra.

Si bien el rasgo de nuestra cultura es la alienación en la idea del éxito individual y profesional, así como la búsqueda de acumulación de experiencias como antes se perseguía la del capital, ella, como toda cultura, todavía es capaz de "saber y percibir" (Ricoeur, 2015, p. 198). Este hecho la faculta para que haga lo propio y module éticamente los procesos políticos y económicos. ¿Qué alcanza a ver la cultura cuando siente la necesidad de relacionarse con lo exótico, con lo muy otro que desconozco, pero que en su gesto me sustrae de mí mismo y de mi miseria? ¿Por qué las formas visitadas, conocidas y reproducidas hasta el fetiche y lo falaz me atan y me ponen en continua guardia para defenderlas? ¿Qué conoce la cultura sobre estas preguntas y las necesidades humanas? Pero, para que la cultura hable hay que abrir un campo participativo y no meramente representativo: "ese llamado a otro, vuelto hacia mí mismo, es la apuesta en cuestión esencial que crea el espacio de la reflexión y el espacio de la libertad" (Ricoeur, 2015, p. 255).

Dicha espacialidad de apertura semántica y vivencial de la libertad supone hacerle frente a la injusticia, la discriminación, la humillación y la indignidad. 
De esta manera, se posibilita que, en medio de la crisis, emerjan otros actores y otras actuaciones que permitan reconstruir, formular y legitimar alternativas para una sociedad más justa y libre (de Sousa Santos, 2009) en la cual se conciba una cultura en ampliación de la comprensión del mundo y en su infinita diversidad expresada en múltiples maneras de pensar, sentir, actuar y relacionarse con la existencia. Hablar de cultura implica, entonces, al ser humano libre y no al individuo como "cosa sometida a las leyes del mercado" (Ricoeur, 2015, p. 260). En este sentido, requiere una simetría que no se basa en el poder adquisitivo y de producción, sino en el reconocimiento del otro en mí: habla con mi voz, pues participa de la humanidad como yo lo hago, aunque en otra piel y desde otras circunstancias y urgencias.

La inclusión del otro, propia de esta economía política, es una relación de verticalidad que "significa que dicho orden político se mantiene abierto a la igualación de los discriminados y a la incorporación de los marginados sin integrarlos en la uniformidad de una comunidad homogeneizada" (Habermas, 1999, p. 118). Esta mantiene al otro en un estereotipo de incapacidad e infantilismo que no solo violenta su libertad, sino la mía, pues quedamos suspendidos en un lugar donde no hay comunicación ni actuación conjunta. Desde esta lógica es posible ver la continuidad de un concepto de cultura que permanece supeditada a una "tensión dialéctica, es decir, contradictoria o agonal, no admite ninguna forma lúdica de la multiplicidad" (Han, 2018b, p. 38) y "solo permite diferencias que estén en conformidad con el sistema" (Han, 2018c, p. 49).

En esta tradición, la cultura es relegada a uno de los tantos ministerios estatales y a la industria cultural que la ofrece como "yuxtaposición" (Han, 2018b, p. 84) de lo diverso para llevar a cabo "la función civilizadora de la democracia de las fronteras y de los empresarios, cuya sensibilidad para las diferencias de orden espiritual no fue nunca excesivamente desarrollada" (Horkheimer y Adorno, 2009, p. 2012). Por el contrario, el encuentro político entre sujetos de la cultura en el que la "otredad, su manera de ser" (Han, 2018f, p. 76) tiene el despliegue y la apertura para la actividad y toma de decisiones, abre el espacio para un ejercicio de libertad verdadero: de elección "entre las posibilidades (alternativas) reales existentes" (Fromm, 1966, p. 189). Este enfoque participativo incrementa tanto la libertad del ciudadano como la posibilidad de libertad de las naciones al crear el espacio de poder estatal:

Que configura el futuro del otro, y no aquel que lo bloquea. En lugar de proceder contra una determinada acción de otro, el poder influye o trabaja sobre el entorno de la acción o sobre los preliminares de la acción del otro, de modo que el otro se decide voluntariamente, también sin acciones negativas, a favor de lo que se corresponde con la voluntad del yo. Sin hacer ningún ejercicio de poder, el soberano toma sitio en el alma del otro. (Han, 2018e, p. 14) 
La metáfora del soberano nos indica, en el sentido de este texto, comunidad. En ella el poder se estructura a partir de la reafirmación del yo y del otro en el espacio público, donde el decir y el hacer, en el reconocimiento mutuo, constituyen redes de sentido que impulsan la acción común: "una manera afortunada de subrayar la primacía ética del vivir-juntos sobre las restricciones vinculadas a los sistemas jurídicos y a la organización política es la de señalar, con Hannah Arendt, la distancia que separa el poder-en-común de la dominación" (Ricoeur, 1996, p. 203). El poder, en este sentido, no lo detenta un exterior encarnado por el líder sobre el súbdito, sino que es constituido y ejercido por el individuo de cultura que, en la "transposición de lo privado a lo público" (Han, 2018c, p. 120) durante la socialización, crea lugares de reconocimiento, emociones colectivas y obras con sentido de lo humano. La obra, aquí, es la acción en "vinculación que se establece en la comunidad" (Sennett, 2012, p. 85) y que tiene que "conducir a alguna parte" (Sennett, 2012, p. 85), esto es, al poder-en-común. Y, aunque parezca una simplicidad y anacronismo hablar de cultura y espacio público en la sociedad de la Modernidad tardía, es claro y amenazante el riesgo que corre el hombre cuando habita una sociedad desgarrada en proyectos del yo sin un horizonte común. Con ello, alimenta "una cultura de la imagen de ese yo idealizado capaz de prosperar en un mundo de compra apalancada. Esta persona idealizada evita la dependencia, no se ata a otros" (Sennett, 2007, p. 44). Se constituye, así, un sistema que impide "que las personas sean expresivas entre ellas" (Sennett, 1978, p. 41). Sin la expresión en el seno de lo cultural, no hay identificación. Sin identificación no hay emociones "como factores estabilizadores" (Nussbaum, 2014, p. 38, 39) de los principios políticos, ni impacto en la esfera de lo social y de lo político para dar paso al conflicto y a las tensiones necesarias que den génesis al cuidado y a la discusión de lo profundamente humano. Por ende, la posibilidad de la libertad se extingue en una sensación que no encuentra asiento firme, pues ella es manifestación de lo social vinculante.

\section{Conclusión}

Con todo este desarrollo conceptual que pone en escena la plasticidad con que se puede llegar a significar la experiencia de la libertad, la cultura en la acción política — que reafirma y reposiciona al ser humano en el lugar que ocupa en el mundo- permite y promueve, desde normativas y políticas de Estado justas, el despliegue de la personalidad que se ha nutrido y ejercitado en la relación con el otro, ya no en esa relación de verticalidad que encuentra minorías, marginados y personas en estado de pobreza o diversidades consumibles por los medios de comunicación masiva. Quizás, aquí, hasta la libertad de los ilustrados tenga su tiempo en la apertura sincera y fraterna hacia el otro que, con su visión del mundo, también construye la complejidad de la realidad humana a la que nadie puede renunciar sin generarle daño o provocar su destrucción. 
Se abre, entonces, un interesantísimo reto intelectual de visibilizar, desde la abundancia epistemológica ensombrecida por las posturas y perspectivas eurocéntricas que declaran una historia universal de los seres humanos, un panorama plural del conocimiento desde nuevas narrativas que nombran el presente en sus vínculos con el pasado y en sus desafíos con el futuro. Estas nuevas vías lingüísticas permiten la transición de las cegueras nominales diseñadas y definidas por el andamiaje ideológico de los diversos modos de producción clasista hacia la emancipación en clave de un camino autorreflexivo y autotransformativo que permita la sostenibilidad de la vida. Se trata de una auténtica experiencia de la libertad que pueda alcanzar un sentido desmarcado de todas las formas de opresión y condición que la han convertido en un trofeo de las ostentosas vitrinas del consumo. La libertad, en la pluralidad de historias que hacen posible la utopía y la acción de un cuerpo en el terreno dialéctico de la existencia, encuentra alternativas para una vida en franco encuentro con la libertad sostenida por la dignidad y la justicia.

En virtud de lo anterior y en develamiento de los sesgos ideológicos que han delimitado la libertad en unas condiciones de posibilidad regidas por las aperturas y limitaciones de las formas económicas que trazan los lineamientos de las sociedades y de sus principios reguladores, se pueden atisbar los diseños políticos y culturales que han instalado a los seres humanos en unos guiones y prácticas en conformidad con los intereses que sostienen las tensiones sociales dentro de un orden de dominación, control, vigilancia y adoctrinamiento de conductas.

Por ello, en todo el dinamismo semántico y vivencial de la libertad queda abierto el sendero reflexivo que nos pone frente a las crisis que desnudan las injusticias y ponen en la escena política nuevas problemáticas para ser abordadas; nuevas voces y acciones para repensar el sistema y evaluar los procesos que han regido el devenir de los seres humanos. En el marco de este capitalismo despiadado, de sus lógicas de explotación, discriminación, humillación y sometimiento, es posible encontrar el desbordamiento de los límites en la manifestación extrema de las crisis que logran ser nombradas y reprochadas desde gestos colectivos que le dicen no más al estado dominante causante de las condiciones de opresión y miseria.

En las miradas del sur (de Sousa Santos, 2009), como territorio simbólico de las contemplaciones y las comprensiones de las inmensas mayorías excluidas y desconocidas en su derecho a la libertad, se visualizan nuevas rutas interrogativas para pensar una hermenéutica libertaria desde las voces y los sentires de los pueblos; desde los silencios condenados al empobrecimiento; desde los sujetos invisibilizados en su dignidad; desde las historias desconocidas, ignoradas, excluidas: borradas de los megarrelatos con los cuales Occidente 
declara una historia universal y un molde para convocar a las competencias por el éxito y la rentabilidad. En este tiempo de agobio e inconformidad, emergen otros actores y otras actuaciones que revelan nuevos y grandes retos para generar alternativas que le brinden esperanza a una sociedad más justa y libre en la que pueda tener lugar la diversidad en sus múltiples maneras de pensar, sentir, actuar y habitar el mundo.

\section{Referencias}

Arendt, A. (1996). Entre el pasado y el futuro. Ocho ejercicios sobre la reflexión política. Ediciones Península.

Arendt, A. (2005). La condición humana. Ediciones Paidós.

Arendt, A. (2008). La promesa de la política. Ediciones Paidós.

Bentham, J. (1836). Deontología o ciencia de la moral. Librería de Mallen y Sobrinos.

Berlin, I. (1983). Conceptos y categorías. Ensayos filosóficos. Fondo de Cultura Económica.

Berlin, I. (2014). Las ideas políticas en la era romántica. Fondo de Cultura Económica.

Bueno, G. (1996). El sentido de la vida. Pentalfa Ediciones.

Cassirer, E. (1972). Filosofía de la Ilustración. Fondo de cultura Económica.

Foucault, M. (2007) Nacimiento de la biopolítica. Fondo de Cultura Económica.

Foucault, M. (2006) Seguridad, territorio y población. Fondo de Cultura Económica.

Fromm, E. (1996). El corazón del hombre. Fondo de Cultura Económica.

Fromm, E. (2019). El miedo a la libertad. Ediciones Paidós; Espasa Libros.

Grondin, J. (2008). ¿Qué es la hermenéutica? Herder.

Grocio, H. (1925). Del derecho de la guerra y de la paz. Editorial Reus.

Habermas, J. y Rawls, J. (1998). Introducción de Vallespín, F. Debate sobre el liberalismo político. Ediciones Paidós.

Habermas, J. (1999) La inclusión del otro. Estudios de teoría política. Ediciones Paidós.

Han, B. (2012). La sociedad del cansancio. Herder Editorial.

Han, B. (2013). La sociedad de la transparencia. Herder Editorial.

Han, B. (2018a). En el enjambre. Herder Editorial.

Han, B. (2018b). Hiperculturalidad. Herder Editorial.

Han, B. (2018c). La expulsión de lo distinto. Herder Editorial.

Han, B. (2018d). Psicopolítica. Neoliberalismo y nuevas técnicas de poder. Herder Editorial.

Han, B. (2018e). Sobre el poder. Herder Editorial.

Han, B. (2018f). Topología de la violencia. Herder Editorial. 
Horkheimer, M. y Adorno. T. (2009). Dialéctica de la Ilustración. Fragmentos filosóficos. Editorial Trotta. Hume, D. (1980). Investigación sobre el conocimiento humano. Alianza Editorial.

Hume, D. (2014). Investigación sobre los principios de la moral. Alianza Editorial.

Kant, I. (2012). Fundamentación para una metafísica de las costumbres. Alianza Editorial.

Kant, I. (2016). La paz perpetua. Alianza Editorial.

Kant, I. (2004). ¿Qué es la Ilustración? Alianza Editorial.

Locke, J. (2014). Segundo tratado sobre el Gobierno Civil. Un ensayo acerca del verdadero origen, alcance y fin del Gobierno Civil. Alianza Editorial.

Mill, J. (2014). El utilitarismo. Alianza Editorial.

Mill, J. (2013). Sobre la libertad. Alianza Editorial.

Montesquieu, C. (2007). Del espíritu de las leyes. Tecnos.

Nietzsche, F. (2014). La genealogía de la moral. Alianza Editorial.

Nussbaum, M. (2014). Las emociones políticas. ¿Por qué el amor es importante para la justicia? Ediciones Paidós; Espasa Libros.

Nussbaum, M. (2007). Las fronteras de la justicia. Consideraciones sobre la exclusión. Ediciones Paidós.

Nussbaum, M. (2020). La tradición cosmopolita. Un noble e imperfecto ideal. Paidós; Editorial Planeta.

Onfray, M. (2016) Los ultras de las luces. Contrahistoria de la filosofía, IV. Editorial Anagrama.

Paine, T. (1984). Derechos del hombre. Alianza Editorial.

Pagden, A. (2002). La ilustración y sus enemigos. Dos ensayos sobre los orígenes de la Modernidad. Ediciones Península.

Rawls, J. (s. f.) Sobre las libertades. Ediciones Paidós.

Ricoeur, P. (1996). El sí mismo como otro. Siglo XXI Editores.

Ricoeur, P. (2015). Historia y verdad. Fondo de Cultura Económica.

Rorty, R. (1989). La filosofía y el espejo de la naturaleza. Ediciones Cátedra.

Rousseau, J. (2007). El contrato social o principios de derecho político. Editorial Tecnos Grupo Anaya.

De Sousa Santos, B. (2009). Una epistemología del sur. Editorial Siglo XXI.

Sennett, R. (1978). El declive del hombre público. Ediciones Península.

Sennett, R. (2012). Juntos. Rituales, placeres y política de cooperación. Editorial Anagrama.

Sennet, R. (2007). La cultura del nuevo capitalismo. Editorial Anagrama.

Smith, A. (2017). La riqueza de las naciones. Alianza Editorial.

Stalin, J. (1976). El marxismo y los problemas de la lingüística. Ediciones en Lenguas Extranjeras.

Weber, M. (2011). La ética protestante y el espíritu del capitalismo. Fondo de Cultura Económica. 